\title{
Erratum to: Multiple Scales of Influence on Wetland Vegetation Associated with Headwater Streams in Alaska, USA
}

Dennis F. Whigham • Coowe M. Walker • Ryan S. King •

Steven J. Baird

Published online: 27 April 2012

(C) Society of Wetland Scientists 2012

Erratum to: Wetlands (2012)

DOI 10.1007/s13157-012-0274-z

The correct version of figure 3 is published here.

Fig. 3 The distribution of Calamagrostis canadensis IV values on Axis 2

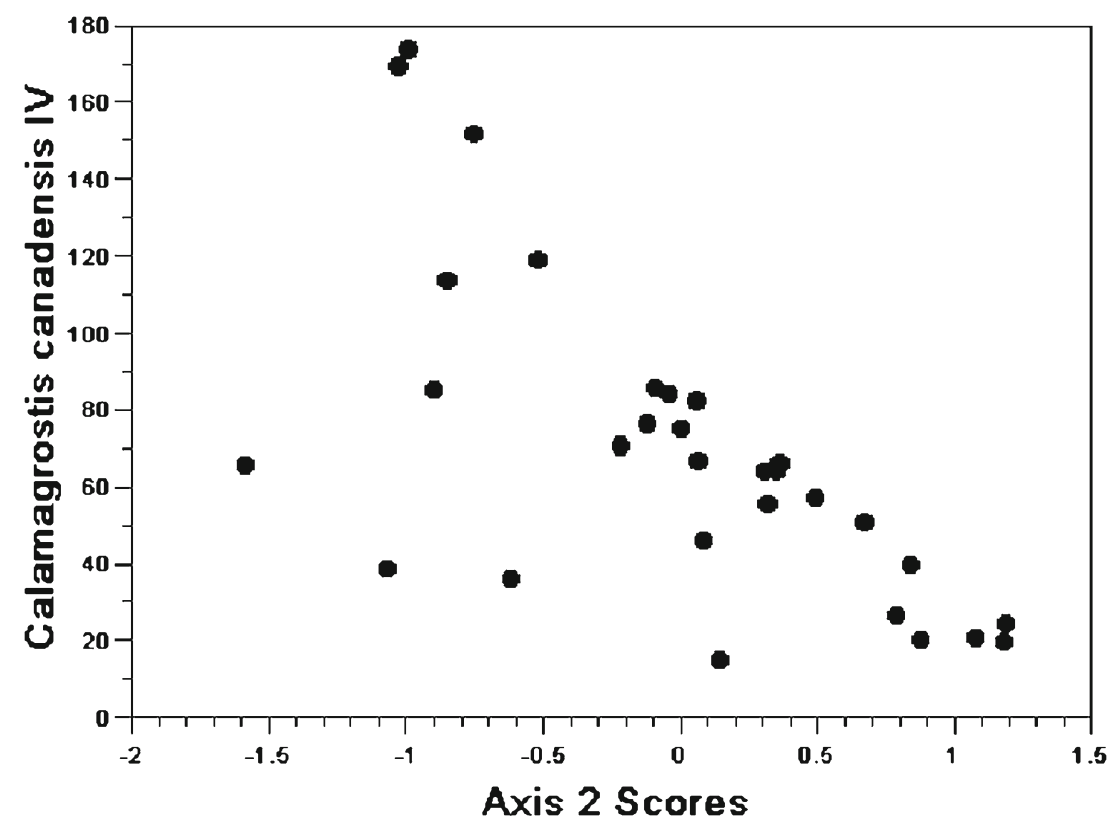

The online version of the original article can be found at http:// dx.doi.org/10.1007/s13157-012-0274-z.

D. F. Whigham $(\bowtie)$

Smithsonian Environmental Research Center,

P.O BOX 28, 647 Contees Wharf Road,

Edgewater, MD 21037-0028, USA

e-mail: whighamd@si.edu

\section{R. S. King}

Center for Reservoir and Aquatic Systems Research, Department of Biology, Baylor University,

One Bear Place 97388,

Waco, TX 76798-7388, USA

C. M. Walker · S. J. Baird

Kachemak Bay Research Reserve,

95 Sterling Highway, Suite 2,

Homer, AK 99603, USA 